\title{
40 years of bovine IVF in the new genomic selection context
}

\author{
Marc-André Sirard \\ Centre de Recherche en Reproduction, Développement et Santé Intergénérationnelle (CRDSI), Département des \\ Sciences Animales, Faculté des Sciences de l'Agriculture et de l'Alimentation, Université Laval, Québec, Canada
}

Correspondence should be addressed to M-A Sirard; Email: Marc-Andre.Sirard@fsaa.ulaval.ca

\begin{abstract}
The development of a complex technology such as in vitro fertilization (IVF) requires years of experimentation, sometimes comparing several species to learn how to create the right in vitro environment for oocytes, spermatozoa and early embryos. At the same time, individual species characteristics such as gamete physiology and gamete interaction are recently evolved traits and must be analysed within the context of each species. In the last 40 years since the birth of Louise Brown, IVF techniques progressed and are now used in multiple domestic and non-domestic animal species around the world. This does not mean that the technology is completely matured or satisfactory; a number of problems remain to be solved and several procedures still need to be optimized. The development of IVF in cattle is particularly interesting since agriculture practices permitted the commercial development of the procedure and it is now used at a scale comparable to human IVF (millions of newborns). The genomic selection of young animals or even embryos combined with sexing and freezing technologies is driving a new era of IVF in the dairy sector. The time has come for a retrospective analysis of the success and pitfalls of the last $\mathbf{4 0}$ years of bovine IVF and for the description of the challenges to overcome in the years to come.

Reproduction (2018) 156 R1-R7
\end{abstract}

\section{Introduction}

The first human IVF baby was born 40 years ago, and the technology has since been applied to several other species including cattle. Initially, the objective of IVF in cows was similar as in humans: the treatment of infertility. Some success was achieved with animals showing pathological infertility, but most of the development and applications of the methodology were oriented towards improving genetic selection and decreasing generation interval (Bousquet et al. 1999). The commercial application of these methods has been fuelled by 40 years of research performed mainly with oocytes obtained at slaughterhouses and frozen semen (sperm), resulting in a very powerful model for clinical application for cows and also for humans. Several excellent reviews have been already published about IVF in different species, focussing on the early days of the technologies (Bavister 2002) or applied industrial aspect in cattle (Hasler 2014) as well as the problems related to the use of IVF in cattle (Hansen 2006, Lonergan \& Fair 2008). The following review will recapitulate the important steps, pitfalls and progresses made during these four decades focussing on cattle IVF (Fig. 1).

\section{The initial challenges (1980-1990)}

Although reproductive biologists were experimenting with IVF in rodents since the fifties (Austin 1951, Chang
1959), the birth of Louise Brown in 1978 created tremendous interest and an intensification of efforts to make it work in other large mammals including the cow. The exceptional work that occurred in the last century that led to the development of IVF is well reviewed in a paper by Sir Robert Edwards (Edwards 1996), who was a pioneer in the observation of immature oocytes from bovine and other mammals in the sixties (Edwards 1965) and received the Nobel Prize in Physiology or Medicine in 2010 for the development of IVF.

Since the procedure leading to the birth of the first IVF baby in humans involved the recovery of mature eggs, initial efforts focused on also obtaining mature eggs from cows using laparotomy and eventually laparoscopy. The world's first IVF calf was produced by the group of Benjamin Brackett using mid-ventral surgery for oocyte recovery and for transfer of embryos to the oviducts (Brackett et al. 1982). It took four more years to develop laparoscopic recovery of oocytes and surgical transfer of blastocysts to the uterus after a seven-day incubation in a rabbit oviduct (Sirard \& Lambert 1986). Laparoscopic recovery of oocytes permitted the use of IVF for the treatment of infertility and the possibility of transfer into the uterus, and opened the use of the technology in a clinical context.

Laparoscopy remained the preferred technique for the clinical application of IVF to infertile cows during the first 10 years but was later replaced by ultrasound. The 'explosion' in the use of IVF for research purposes 
1

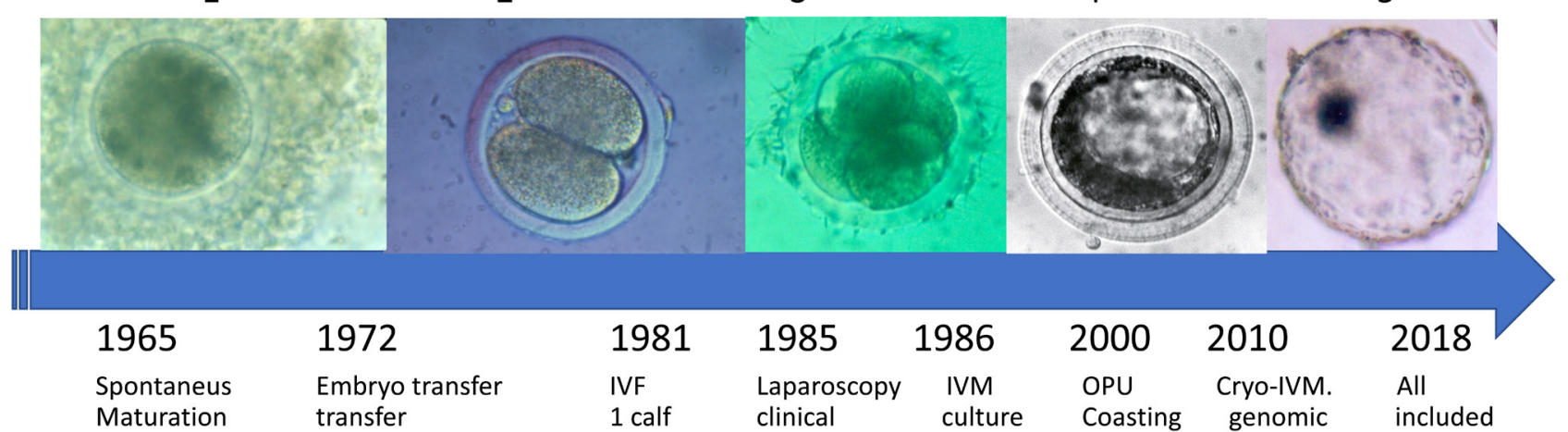

Figure 1 The chronology of important steps in bovine IVF, with very early images in-vitro-matured oocyte (1) or of embryos from in-vivo matured oocytes (2-3-4) and bovine embryos incubated in a rabbit oviduct for several days (4). All included means that it is now possible to add all these techniques and obtain acceptable success.

resulted from the possibility of using oocytes obtained from slaughterhouses. This was developed in several locations in Europe and the United States at about the same time with quite similar protocols (reviewed by Greve \& Madison 1991). The discovery of the stimulatory effect of heparin on the capacitation of bovine spermatozoa in vitro was also instrumental in the rapid increase in fertilization and success rates (Parrish et al. 1985) review in 2014 (Parrish 2014). The effect of heparin also partially explained the great success of laparoscopic oocyte recovery since this procedure requires the use of an anticoagulant in the needle rinsing medium to prevent coagulation in the $60-\mathrm{cm}$ laparoscope used on cows. The discovery of the heparin effect was accidental and was understood only two years later when John Parrish published his work (Parrish et al. 1986). The heparin although not truly present in the oviduct could mimic some follicular fluid constituents like proteoglycans (Parrish et al. 1985). The initial work came for the study of follicular fluid components by the group of Roy Ax (Handrow et al. 1982). On the oocyte side, the challenge was to find optimal culture conditions as Robert Edwards had already shown the capacity of oocytes to resume meiosis spontaneously in vitro. Surprisingly, the first media to be largely used have remained the same for over 30 years. Indeed, most laboratories still use TCM-199 supplemented with serum, FSH and oestradiol for IVM as developed in Neal First's laboratory (Ball et al. 1984, Sirard et al. 1988), as well as Tyrode-Lactate medium for sperm washing and sperm/egg co-incubation. The situation is quite different for the embryo culture medium which was modified several times in the first ten years (for review see: Greve \& Madison 1991) and is still changing today. The challenge was and remains the dynamic condition during the first few days of embryonic development in the oviduct and the adaptation of the embryo metabolism to the preand post-genome activation transition. In fact, the initial successes of bovine IVF were obtained with a transient incubation of embryos in the oviducts of rabbits (Sirard \& Lambert 1986) or sheep (Lu et al. 1987). Incubation into oviducts was eventually replaced with co-culture with oviductal cells which was initially required to pass the 8-cell block in bovine embryos (Gandolfi \& Moor 1987, Eyestone \& First 1989). Therefore, a sequential approach as in humans, where the medium composition is modified at the time of embryonic genome activation, has been privileged with two or three medium changes in the period of development from one-cell embryos to blastocyst (Felmer et al. 2011). The progressive definition of the optimal components of the ideal medium began with the analysis of the oviductal environment and the preparation of a synthetic oviductal fluid (SOF) (Tervit et al. 1972) which was rapidly adopted (Bondioli \& Wright 1980) and initially supplemented with serum or BSA (Thompson et al. 1989), but eventually enriched with specific amino acids (Keskintepe et al. 1995) to allow the development of one-cell embryos to blastocysts in defined or semi-defined (BSA) conditions. What has remained puzzling and to some extent unique to bovine is the requirement for group culture ( $\mathrm{O}^{\prime}$ Doherty et al. 1997) although some success has been obtained with single culture in presence of serum (Hagemann et al. 1998). Although some mechanical conditions like micro fluidics (Krisher \& Wheeler 2010) or very small culture drops or using the micro well approach (Rienzi et al. 2011) have been used to decrease the dispersion of autocrine factors, such factor has not been identified yet.

\section{The achievement of IVM (1990-2000)}

Following the very few publications on IVF using in-vivomatured oocytes, the potential of using oocytes obtained from slaughterhouses became a very active research field. It was known that the oocyte maturation process was different from the follicular maturation process and that the latter could be reproduced in vitro much more easily than the former (Thibault 1977). The groups of 
I. Gordon in Ireland (Lu et al. 1987) and Neal First in the United States (Ball et al. 1984, Leibfried-Rutledge et al. 1985, 1987, Sirard et al. 1988) were amongst the most active at testing culture conditions for these oocytes. It was rapidly observed that nuclear maturation was quite automatic in most culture conditions and within $24 \mathrm{~h}$, the rate of metaphase II oocytes was over $85 \%$ (Sirard et al. 1989). Therefore, as early as the late eighties, obtaining hundreds of embryos per experiment using slaughterhouse material was a true possibility. This almost unlimited source of oocytes in cattle and pigs was instrumental to the development of better techniques and culture conditions compared to other species where progress has been slower like horses and IVF is still limited by the sperm failure to fertilize in vitro requiring injection of spermatozoa into the oocyte (Leemans et al. 2016) or pets where seasons and physiological peculiarities alter the success of IVF (Van Soom et al. 2014).

With use of slaughterhouse oocytes to generate embryos, it was noted that different culture media could affect the phenotype of offspring. The large offspring syndrome was initially observed in sheep, then replicated in cows and was associated with the presence of serum in culture media post fertilization. We now know that this phenomenon is epigenetic in nature and is exacerbated when embryos are generated by cloning, either with blastomeres fused to enucleated oocytes (Willadsen 1989) or when fused to somatic nuclei (Farin et al. 2004). The incidence of the phenotype is difficult to estimate today as it can be mild with a few more days in gestation length, or it can be extreme including stillbirth with abnormal calf weight and placental anomalies (Siqueira et al. 2017). In a large Brazilian operation where oocytes are obtained by ovarian pick up using ultrasound-guided aspiration without hormonal stimulation of the donors, a recent survey based on 15,000 births (including control Al) indicated an average increase in birth weight of $1 \mathrm{~kg}$ for IVF calves (Pietro Baruselli, unpublished observation).

For many years, doubt remained that defined media, although allowing the culture up to the blastocyst stage, were the major cause of limited developmental competence of oocytes. Indeed, from 1990 to 2000, the average success rate plateaued at $30-40 \%$ of oocytes developing to the blastocyst stage despite the addition of hundreds of different products, cytokines, growth factors, anti-oxidants, in addition to the introduction of new types of incubators, and reduced oxygen tension. Very few of these conditions were ever tested with in vivo transfers (Hansen 2006, Lonergan et al. 2006). Then, attention turned towards the source of oocytes as a potential explanation for the limited success rates of IVF.

The morphology of oocyte-cumulus complexes obtained when all follicles are aspirated form ovaries at slaughter varies greatly. In cows, follicles are growing in waves principally under the influence of $\mathrm{FSH}$. The oestrous cycle of 21 days includes two, or sometime three, waves of growth, each leading to the selection of one dominant follicle over $9 \mathrm{~mm}$ (Ginther et al. 1997). When FSH starts to rise, the most advanced follicle is likely the one that will become dominant, while the smaller ones will grow for a few days under FSH support and then will start an atresia process as the FSH level drops (Ginther et al. 1989). This cohort phenomenon occurs from puberty to death and even during pregnancy. Therefore, if ovaries are collected at random at slaughter, most follicles will be between $3 \mathrm{~mm}$ and $9 \mathrm{~mm}$ and they contain the population of oocytes available for IVMIVF. The effect of size becomes more important starting at $8 \mathrm{~mm}$ (Hendriksen et al. 2000); but even if oocytes come from larger follicles, success is not guaranteed. Because the atresia process is progressive and takes time, approximately one-third of the antral follicles in random ovaries will be in the FSH-dependant growing phase, one-third will be in the plateau phase when FSH decreases, and one-third will be more advanced in the atresia process (Douville \& Sirard 2014). This situation is reflected in the morphology of the cumulus-oocyte complexes recovered from these follicles and is partially associated with outcome (Blondin \& Sirard 1995). A very compact and bright cumulus indicates that the follicle of origin was in the growth phase and the oocyte is not fully competent. Early expansion of the cumulus can be associated with the plateau phase and the outcome is better but still far from $100 \%$. Finally, oocytes with a partially denuded or atretic-like cumulus have a lower competence compared to the plateau group (Sirard 2011). Oocytes from pre-ovulatory follicles sometimes demonstrate higher developmental potential (Dieleman et al. 2002), but because dominant follicles are not all ovulated, the majority disappear in the atresia process, and the same phenomenon of variable quality is observed (Sirard 2011). These observations were instrumental in the development of pre-ovum pick up animal treatments that began in the nineties.

\section{The improvement of animal pre-treatments (2000-2010)}

When ovarian stimulation was used prior to oocyte recovery but no hCG given in order to allow in vitro maturation of these oocytes, the success rate varied enormously independent of the culture conditions (Hendriksen et al. 2000, Dieleman et al. 2002). Indeed, the aspiration of oocytes during the growing phase of the follicles under FSH stimulation was associated with much reduced developmental competence (Blondin et al. 1996), while the arrest of FSH for 2-3 days prior to aspiration created a window of $\mathrm{LH}$-supported growth (for follicles over $9 \mathrm{~mm}$ ), enabling them to generate oocytes of very high developmental potential (Blondin et al. 1997a). This later experiment demonstrated the 
excellent performance of the culture medium since with the right oocyte population, blastocyst rates over $80 \%$ could be reached (Blondin et al. 2002). Surprisingly, it was also noted during these experiments that the postmortem incubation of ovaries at body temperature (during transport and holding) resulted in a gain of developmental competence compared to oocytes aspirated immediately after slaughter (Blondin et al. 1997b). This phenomenon was later associated with the induction of post-LH conditions, and more recently with the transfer of RNA molecules from the cumulus to the oocyte (Macaulay et al. 2016). These results led to the development of a new protocol to treat cows before oocyte aspiration. The concept is to create a wave of dominant follicles using FSH stimulation (ideally after removing any follicles over $5 \mathrm{~mm}$ to synchronize the population to be stimulated) and continue stimulation until most of the follicles have reached the stage when $\mathrm{LH}$ receptors appear $(8 \mathrm{~mm}$ in bovine (Ginther et al. 1997)), and then mimicking the rest of the natural cycle when follicles continue to grow and differentiate without FSH but with basal LH. At that time, the follicular growth pattern changes from a high mitotic period when the total granulosa and theca, cell number increases to a period when the volume is expanded mainly by fluid accumulation with a lower mitotic index (Girard et al. 2015). This post-FSH period is associated with an increase in oocyte quality as measured by the blastocyst rates observed after IVF (Blondin 2002). However, following these observations, it remained unclear if competence would be maintained throughout ovulation or, if ovulation was prevented, if oocyte quality would drop as the follicle entered atresia as demonstrated by Dias et al. (2013).

To further improve our understanding of the effects of FSH withdrawal on oocyte quality, a stimulation protocol was built to assess the effects of coasting time on blastocyst rates. A specific design was created in which six animals received the same stimulation regimen followed by four different coasting times (within each animal), followed by oocyte aspiration, IVF and culture. The results confirmed that a longer period of coasting was better than a shorter one $(44$ and $68 \mathrm{~h}$ resulted in more embryos than $20 \mathrm{~h}$ of coasting) and, although not significant, the longer period of coasting $(92 \mathrm{~h})$ resulted in fewer embryos compared to 44 and $68 \mathrm{~h}$ (Nivet et al. 2012). In these experiments, some animals generated groups of oocytes producing $100 \%$ blastocysts, demonstrating unequivocally that culture conditions are not detrimental when oocyte quality is excellent. Moreover, tissue samples were obtained from the three compartments (oocyte-cumulus-granulosa) and were instrumental in the resolution of the physiological processes occurring during this final transformation (Khan et al. 2016).

In a paper addressing the limitations of IVF Patrick Lonergan stated that 'there is considerable evidence of a significant influence of follicular origin on oocyte developmental potential and it appears that once the oocyte is removed from the follicle its developmental capacity is capped' (Lonergan \& Fair 2008). I totally agree with the latter statement and I believe that there is still much improvement possible in the pre-conditioning follicles prior to oocyte aspiration.

\section{The genomic effect (2010-2020)}

In this last section, two aspects of the genomic revolution will be discussed: first, the genomic analysis of the follicles, oocytes and the embryos generated from IVF using transcriptomic and epigenetic tools and second, the impact of genomic selection on the use of IVF in cattle.

From the early days of IVF, it was obvious that in-vitromatured oocytes and in-vitro-produced embryos looked and behaved differently. For example, several studies show that in-vitro-produced embryos are less competent to implant and more sensitive to cryopreservation compared to in-vivo-produced embryos (Pryor et al. 2011). With the development of genomic tools, the capacity to analyse embryos from the one-cell to blastocyst stage provided a new angle to compare in vivo and in vitro aspects. Several studies have used microarray or RNAseq technologies on embryos cultured in multitudes of different conditions to compare to in vivo control embryos. Most of the studies mentioned in the following and the conditions used are now summarized at a web site from the Canadian EmbryoGENE Network (http://emb-bioinfo.fsaa.ulaval.ca/IMAGE/).

The work of Tesfaye in Bonn (Gad et al. 2012) generated the most comprehensive data set by analysing each developmental steps individually (IVM, fertilization, early cleavage, MET (maternal to embryo transition) morula and blastocysts)) by comparing gene expression in embryos alternatively cultured in vitro and in vitro The results indicated that embryos are particularly sensitive to in vitro conditions at the 4-cell and morula stages (Gad et al. 2012). The same group then analysed the DNA methylation of blastocysts obtained from different combinations of in vitro and in vivo periods to demonstrate a progressive increase in DMR (differently methylated regions) with time spent in vitro (SalilewWondim et al. 2015). The culture conditions also impacted the transcriptome, and the presence of specific amounts of sugars, lipids or reactive oxygen species resulted in changes in gene expression (see review from Cagnone and Sirard (2016)) and in DNA methylation (Tremblay et al. 2017). These tools are obviously very sensitive, but the differences observed were partially expected as the in vitro environment will never be completely similar to in vivo. The changes observed are part of the adaptation to this different environment and the better embryos produced in vitro will always have differences from the in-vivo-produced ones. 
Not surprisingly, the pregnancy rates are slightly affected by IVF as there are more embryonic and foetal losses with embryos from IVF than artificial insemination or embryo transfer from in vivo origin (Taverne et al. 2002), and more recently some post-natal phenotypes are described but more with sexed sperm and recipient than IVF per se (Siqueira et al. 2017).

In all species studied, offspring obtained by IVF are somewhat different from naturally conceived ones. A recent special issue of the Journal of Developmental Origins of Health and Disease covered the effects of artificial reproductive technologies in many species including the cattle (Sirard 2017). As for the serum effect noted in the nineties, the epigenetic effect of culture is worrisome even if millions of healthy calves and human babies have been born so far. Clearly, more research is needed to better measure, follow-up and understand the potential consequences for health in later life.

\section{Genomic selection}

The selection of the most valuable individuals using the genomic tools (haplotypes maps) was introduced in early 2010 and allows rapid modification of specific breeds. Although the objectives and decisions using genomic selection remain similar to the phenotype analysis, the speed of progress is enhanced by the ability to obtain information at the blastocyst stage. The precise identification of the characteristics desired in animals that make up the next generation created a rapid rise in demand for new artificial reproduction techniques to rapidly select and multiply the animals possessing the desired traits. Initially, proven bulls (5 years and more) and proven cows (3 years and more) were selected for IVF; but now, with genomic analysis performed soon after birth, the genetic value of the bull is known immediately and as soon as semen can be produced, the bull can be selected as a sire for IVF, often using sexing technologies to improve the efficiency of producing females of the right genomic/ genetic background. The same is true on the female side, with the difference that oocytes can now be collected before puberty with relatively high success (Landry et al. 2016). This 'genomic bubble' is now driving the development of several IVF laboratories in North America and elsewhere in the world. The number of IVF-produced embryos was on a constant rise in the last 10 years and following the millions of embryos transferred in the beef industry in South America, we now see a rapid increase in dairy embryos generated by IVF. An additional incentive to use IVF is the possibility to use sexed semen in vitro, which makes some bulls more affordable by using much less semen per batch of embryos (Blondin et al. 2009). The new possibility of cryopreserving IVF embryos also opens the door to perform embryo biopsies for genomic analysis and the selection of only the best combinations for transfer.
Suddenly, all of the work invested in the optimization of the IVF process culminates in a very efficient procedure to improve genomic merit more rapidly. The cumulative steps of IVM, IVF with sexed sperm, culture in defined media, biopsies and cryopreservation must all work almost perfectly to make an efficient pipeline. Since many of these steps are technically complex and sensitive to operators or environment, it remains a challenge to make it commercially viable.

\section{The future of IVF}

Certainly, IVF is not something that will disappear shortly from the animal selection toolbox especially with the list of advantages listed earlier such as using sexed semen and genomic selection at the blastocyst stage. New approaches, often developed in human, such as morphokinetics (Kaser \& Racowsky 2014) and aneuploidy screening using genomic (Treff \& Zimmerman 2017) or less invasive techniques as free DNA (Liu et al. 2017), may become affordable in cattle and improve pregnancy rates in the field.

A few years ago, IVF was instrumental to develop embryonic (Westhusin et al. 1991) and then somatic nuclear transfer procedures, mainly for the purpose of genetic selection and modification (Tan et al. 2016). Today, we can foresee the same use of IVF for CRISPRCas-9 related technologies that will allow precise genome editing or even epigenome editing. Indeed, the capacity to access the embryo at the pronuclear stage is important to minimize mosaicism and improve success rates of genome editing (Yum et al. 2018).

\section{Conclusions}

In the last 40 years, bovine IVF has evolved from an experimental procedure to treat infertile animals towards a genomic accelerator for many breeds. The progress in culture, cryopreservation, oocyte preparation and laboratory environment made possible the production of millions valuable animals. Some questions related to the phenotypes of some offspring still require more research to better understand the impact of the seven days spent in vitro, but the technology has matured to a similar scale as we see in human IVF and will probably be around for several more decades.

\section{Declaration of interest}

I declare that there is no conflict of interest that could be perceived as prejudicing the impartiality of this review.

\section{Funding}

This research did not receive any specific grant from any funding agency in the public, commercial or not-for-profit sector. 


\section{References}

Austin CR 1951 Observations on the penetration of the sperm in the mammalian egg. Australian Journal of Scientific Research. Series B: Biological Sciences 4 581-596.

Ball GD, Leibfried ML, Ax RL \& First NL 1984 Maturation and fertilization of bovine oocytes in vitro. Journal of Dairy Science 67 2775-2785. (https://doi.org/10.3168/jds.S0022-0302(84)81634-3)

Bavister BD 2002 Early history of in vitro fertilization. Reproduction 124 181-196. (https://doi.org/10.1530/rep.0.1240181)

Blondin P \& Sirard M-A 1995 Oocyte and follicular morphology as determining characteristics for developmental competence in bovine oocytes. Molecular Reproduction and Development 41 54-62. (https:// doi.org/10.1002/mrd.1080410109)

Blondin P, Coenen K, Guilbault LA \& Sirard MA 1996 Superovulation can reduce the developmental competence of bovine embryos. Theriogenology 46 1191-1203. (https://doi.org/10.1016/S0093691X(96)00290-7)

Blondin P, Coenen K, Guilbault LA \& Sirard MA 1997a In vitro production of bovine embryos: developmental competence is acquired before maturation. Theriogenology 47 1061-1075. (https://doi.org/10.1016/ S0093-691X(97)00063-0)

Blondin P, Guilbault LA \& Sirard MA $1997 b$ The time interval between FSH-P administration and slaughter can influence the developmental competence of beef heifer oocytes. Theriogenology 48 803-813. (https:// doi.org/10.1016/S0093-691X(97)00303-8)

Blondin P, Bousquet D, Twagiramungu H, Barnes F \& Sirard M-A 2002 Manipulation of follicular development to produce developmentally competent bovine oocytes. Biology of Reproduction 66 38-43. (https:// doi.org/10.1095/biolreprod66.1.38)

Blondin P, Beaulieu M, Fournier V, Morin N, Crawford L, Madan P \& King WA 2009 Analysis of bovine sexed sperm for IVF from sorting to the embryo. Theriogenology 71 30-38. (https://doi.org/10.1016/j. theriogenology.2008.09.017)

Bondioli KR \& Wright RW 1980 Influence of culture media on in vitro fertilization of ovine tubal oocytes. Journal of Animal Science $\mathbf{5 1}$ 660-667. (https://doi.org/10.2527/jas1980.513660x)

Bousquet D, Twagiramungu $\mathbf{H}$, Morin N, Brisson C, Carboneau G \& Durocher J 1999 In vitro embryo production in the cow: an effective alternative to the conventional embryo production approach. Theriogenology 51 59-70. (https://doi.org/10.1016/S0093691X(98)00231-3)

Brackett BG, Bousquet D, Boice ML, Donawick WJ, Evans JF \& Dressel MA 1982 Normal development following in vitro fertilization in the cow. Biology of Reproduction 27 147-158. (https://doi.org/10.1095/ biolreprod27.1.147)

Cagnone G \& Sirard M-A 2016 The embryonic stress response to in vitro culture: insight from genomic analysis. Reproduction 152 R247-R261. (https://doi.org/10.1530/REP-16-0391)

Chang MC 1959 Fertilization of rabbit ova in vitro. Nature 184 (Supplement 7) 466-467.

Dias FCF, Khan MIR, Sirard MA, Adams GP \& Singh J 2013 Differential gene expression of granulosa cells after ovarian superstimulation in beef cattle. Reproduction 146 181-191. (https://doi.org/10.1530/REP-130114)

Dieleman SJ, Hendriksen PJM, Viuff D, Thomsen PD, Hyttel P, Knijn HM Wrenzycki C, Kruip TM, Niemann H, Gadella BM et al. 2002 Effects of in vivo prematuration and in vivo final maturation on developmental capacity and quality of pre-implantation embryos. Theriogenology $\mathbf{5 7}$ 5-20. (https://doi.org/10.1016/S0093-691X(01)00655-0)

Douville G \& Sirard M-A 2014 Changes in granulosa cells gene expression associated with growth, plateau and atretic phases in medium bovine follicles. Journal of Ovarian Research 7 50. (https://doi.org/10.1186/17572215-7-50)

Edwards RG 1965 Maturation in vitro of mouse, sheep, cow, pig, rhesus monkey and human ovarian oocytes. Nature 208 349-351. (https://doi. org/10.1038/208349a0)

Edwards RG 1996 The history of assisted human conception with especial reference to endocrinology. Experimental and Clinical Endocrinology and Diabetes 104 183-204.

Eyestone WH \& First NL 1989 Co-culture of early cattle embryos to the blastocyst stage with oviducal tissue or in conditioned medium. Journal of Reproduction and Fertility 85 715-720. (https://doi.org/10.1530/ jrf.0.0850715)

Farin CE, Farin PW \& Piedrahita JA 2004 Development of fetuses from in vitro-produced and cloned bovine embryos. Journal of Animal Science 82 (Supplement E) E53-E62.

Felmer RN, Arias ME, Muñoz GA \& Rio JH 2011 Effect of different sequential and two-step culture systems on the development, quality, and RNA expression profile of bovine blastocysts produced in vitro. Molecular Reproduction and Development 78 403-414. (https://doi. org/10.1002/mrd.21317)

Gad A, Hoelker M, Besenfelder U, Havlicek V, Cinar U, Rings F, Held E, Dufort I, Sirard M-A, Schellander K et al. 2012 Molecular mechanisms and pathways involved in bovine embryonic genome activation and their regulation by alternative in vivo and in vitro culture conditions. Biology of Reproduction 87 100. (https://doi.org/10.1093/biolreprod/87.s1.100)

Gandolfi F \& Moor RM 1987 Stimulation of early embryonic development in the sheep by co-culture with oviduct epithelial cells. Journal of Reproduction and Fertility $\mathbf{8 1}$ 23-28 (https://doi.org/10.1530/ jrf.0.0810023)

Ginther OJ, Knopf L \& Kastelic JP 1989 Temporal associations among ovarian events in cattle during oestrous cycles with two and three follicular waves. Journal of Reproduction and Fertility 87 223-230. (https://doi.org/10.1530/jrf.0.0870223)

Ginther OJ, Kot K, Kulick LJ \& Wiltbank MC 1997 Emergence and deviation of follicles during the development of follicular waves in cattle. Theriogenology 48 75-87. (https://doi.org/10.1016/S0093$691 \times(97) 00192-1)$

Girard A, Dufort I, Douville G \& Sirard M-A 2015 Global gene expression in granulosa cells of growing, plateau and atretic dominant follicles in cattle. Reproductive Biology and Endocrinology 1317.

Greve T \& Madison V 1991 In vitro fertilization in cattle: a review. Reproduction, Nutrition and Development 31 147-157. (https://doi. org/10.1051/rnd:19910205)

Hagemann LJ, Weilert LL, Beaumont SE \& Tervit HR. 1998 Development of bovine embryos in single in vitro production (sIVP) systems. Molecular Reproduction and Development 51 143-147. (https://doi.org/10.1002/ (SICI)1098-2795(199810)51:2<143::AID-MRD3>3.0.CO;2-Q)

Handrow RR, Lenz RW \& Ax RL 1982 Structural comparisons among glycosaminoglycans to promote an acrosome reaction in bovine spermatozoa. Biochemical and Biophysical Research Communications 107 1326-1332. (https://doi.org/10.1016/S0006-291X(82)80143-5)

Hansen PJ 2006 Realizing the promise of IVF in cattle--an overview. Theriogenology 65 119-125. (https://doi.org/10.1016/j. theriogenology.2005.09.019)

Hasler JF 2014 Forty years of embryo transfer in cattle: a review focusing on the journal Theriogenology, the growth of the industry in North America, and personal reminisces. Theriogenology 81 152-169. (https:// doi.org/10.1016/j.theriogenology.2013.09.010)

Hendriksen PJ, Vos PL, Steenweg WN, Bevers MM \& Dieleman SJ 2000 Bovine follicular development and its effect on the in vitro competence of oocytes. Theriogenology 53 11-20. (https://doi.org/10.1016/S0093691X(99)00236-8)

Kaser DJ \& Racowsky C 2014 Clinical outcomes following selection of human preimplantation embryos with time-lapse monitoring: a systematic review. Human Reproduction Update 20 617-631. (https:// doi.org/10.1093/humupd/dmu023)

Keskintepe L, Burnley CA \& Brackett BG 1995 Production of viable bovine blastocysts in defined in vitro conditions. Biology of Reproduction 52 1410-1417. (https://doi.org/10.1095/biolreprod52.6.1410)

Khan DR, Landry DA, Fournier É, Vigneault C, Blondin P \& Sirard M-A 2016 Transcriptome meta-analysis of three follicular compartments and its correlation with ovarian follicle maturity and oocyte developmental competence in cows. Physiological Genomics 48 633-643. (https://doi. org/10.1152/physiolgenomics.00050.2016)

Krisher RL \& Wheeler MB. 2010 Towards the use of microfluidics for individual embryoculture. Reproduction, Fertility and Development 22 32-39. (https://doi.org/10.1071/RD09219)

Landry DA, Bellefleur A-M, Labrecque R, Grand F-X, Vigneault C, Blondin P \& Sirard M-A 2016 Effect of cow age on the in vitro developmental competence of oocytes obtained after FSH stimulation and coasting treatments. Theriogenology 86 1240-1246. (https://doi.org/10.1016/j. theriogenology.2016.04.064) 
Leemans B, Gadella BM, Stout TAE, De Schauwer C, Nelis H, Hoogewijs M \& Van Soom A 2016 Why doesn't conventional IVF work in the horse? The equine oviduct as a microenvironment for capacitation/fertilization. Reproduction 152 R233-R245. (https://doi.org/10.1530/REP-16-0420)

Leibfried-Rutledge ML, Critser ES \& First NL 1985 Fertilization potential of follicular oocytes classified by stage of cycle and size of follicle. Theriogenology 23 753-759. (https://doi.org/10.1016/0093691X(85)90150-5)

Leibfried-Rutledge ML, Critser ES, Eyestone WH, Northey DL \& First NL 1987 Development potential of bovine oocytes matured in vitro or in vivo. Biology of Reproduction 36 376-383. (https://doi.org/10.1095/ biolreprod36.2.376)

Liu W, Liu J, Du H, Ling J, Sun X \& Chen D 2017 Non-invasive preimplantation aneuploidy screening and diagnosis of beta thalassemia IVSII654 mutation using spent embryo culture medium. Annals of Medicine 49 319-328. (https://doi.org/10.1080/07853890.2016.125 4816)

Lonergan P \& Fair T 2008 In vitro-produced bovine embryos - dealing with the warts. Theriogenology 69 17-22. (https://doi.org/10.1016/j. theriogenology.2007.09.007)

Lonergan P, Fair T, Corcoran D \& Evans ACO 2006 Effect of culture environment on gene expression and developmental characteristics in IVF-derived embryos. Theriogenology 65 137-152. (https://doi. org/10.1016/j.theriogenology.2005.09.028)

Lu KH, Gordon I, Gallagher M \& McGovern H 1987 Pregnancy established in cattle by transfer of embryos derived from in vitro fertilisation of oocytes matured in vitro. Veterinary Record 121 259-260. (https://doi. org/10.1136/vr.121.11.259)

Macaulay AD, Gilbert I, Scantland S, Fournier E, Ashkar F, Bastien A, Saadi HAS, Gagné D, Sirard M-A, Khandjian ÉW et al. 2016 Cumulus cell transcripts transit to the bovine oocyte in preparation for maturation. Biology of Reproduction 9416.

Nivet A-L, Bunel A, Labrecque R, Belanger J, Vigneault C, Blondin P \& Sirard M-A 2012 FSH withdrawal improves developmental competence of oocytes in the bovine model. Reproduction 143 165-171. (https://doi. org/10.1530/REP-11-0391)

O'Doherty EM, Wade MG, Hill JL \& Boland MP 1997 Effects of culturing bovine oocytes either singly or in groups on development to blastocysts. Theriogenology 48 161-169.

Parrish JJ 2014 Bovine in vitro fertilization: in vitro oocyte maturation and sperm capacitation with heparin. Theriogenology 81 67-73. (https://doi. org/10.1016/j.theriogenology.2013.08.005)

Parrish JJ, Susko-Parrish JL \& First NL 1985 Effect of heparin and chondroitin sulfate on the acrosome reaction and fertility of bovine sperm in vitro. Theriogenology 24 537-549. (https://doi.org/10.1016/0093691X(85)90060-3)

Parrish JJ, Susko-Parrish JL, Leibfried-Rutledge ML, Critser ES, Eyestone WH \& First NL 1986 Bovine in vitro fertilization with frozen-thawed semen. Theriogenology 25 591-600. (https://doi.org/10.1016/0093691X(86)90143-3)

Pryor JH, Looney CR, Romo S, Kraemer DC \& Long CR 2011 Cryopreservation of in vitro produced bovine embryos: effects of lipid segregation and post-thaw laser assisted hatching. Theriogenology 75 24-33. (https://doi.org/10.1016/j.theriogenology.2010.07.006)

Rienzi L, Vajta G \& Ubaldi F 2011 New culture devices in ART. Placenta 32 (Supplement 3) S248-S251. (https://doi.org/10.1016/j. placenta.2011.06.018)

Salilew-Wondim D, Fournier E, Hoelker M, Saeed-Zidane M, Tholen E, Looft C, Neuhoff C, Besenfelder U, Havlicek V, Rings F et al. 2015 Genome-wide DNA methylation patterns of bovine blastocysts developed in vivo from embryos completed different stages of development in vitro. PLOS ONE 10 e0140467. (https://doi.org/10.1371/ journal.pone.0140467)

Siqueira LGB, Dikmen S, Ortega MS \& Hansen PJ 2017 Postnatal phenotype of dairy cows is altered by in vitro embryo production using reverse X-sorted semen. Journal of Dairy Science 100 5899-5908. (https://doi. org/10.3168/jds.2016-12539)
Sirard M-A 2011 Follicle environment and quality of in vitro matured oocytes. Journal of Assisted Reproduction and Genetics 28 483-488. (https://doi.org/10.1007/s10815-011-9554-4)

Sirard M-A 2017 The influence of in vitro fertilization and embryo culture on the embryo epigenetic constituents and the possible consequences in the bovine model. Journal of Developmental Origins of Health and Disease 8 411-417. (https://doi.org/10.1017/S2040174417000125)

Sirard MA \& Lambert RD 1986 Birth of calves after in vitro fertilisation using laparoscopy and rabbit oviduct incubation of zygotes. Veterinary Record 119 167-169. (https://doi.org/10.1136/vr.119.8.167)

Sirard MA, Parrish JJ, Ware CB, Leibfried-Rutledge ML \& First NL 1988 The culture of bovine oocytes to obtain developmentally competent embryos. Biology of Reproduction 39 546-552. (https://doi.org/10.1095/ biolreprod39.3.546)

Sirard MA, Florman HM, Leibfried-Rutledge ML, Barnes FL, Sims ML \& First NL 1989 Timing of nuclear progression and protein synthesis necessary for meiotic maturation of bovine oocytes. Biology of Reproduction $\mathbf{4 0}$ 1257-1263. (https://doi.org/10.1095/biolreprod40.6.1257)

Tan W, Proudfoot C, Lillico SG \& Whitelaw CBA 2016 Gene targeting, genome editing: from Dolly to editors. Transgenic Research 25 273-287. (https://doi.org/10.1007/s11248-016-9932-x)

Taverne MAM, Breukelman SP, Perényi Z, Dieleman SJ, Vosa PLAM, Jonker HH, de Ruigh L, Van Wagtendonk-de Leeuw JM \& Beckers J-F 2002 The monitoring of bovine pregnancies derived from transfer of in vitro produced embryos. Reproduction, Nutrition and Development 42 613-624. (https://doi.org/10.1051/rnd:2002047)

Tervit HR, Whittingham DG \& Rowson LEA 1972 Successful culture in vitro of sheep and cattle ova. Journal of Reproduction and Fertility $\mathbf{3 0}$ 493-497. (https://doi.org/10.1530/jrf.0.0300493)

Thibault C 1977 Hammond memorial lecture: are follicular maturation and oocyte maturation independent processes. Journal of Reproduction and Fertility 51 1-15 (https://doi.org/10.1530/jrf.0.0510001)

Thompson JG, Parton GA, Cruickshank GW, Smith JF \& Wales RG 1989 Development of sheep preimplantation embryos in media supplemented with glucose and acetate. Theriogenology 32 323-330. (https://doi. org/10.1016/0093-691X(89)90322-1)

Treff NR \& Zimmerman RS 2017 Advances in preimplantation genetic testing for monogenic disease and aneuploidy. Annual Review of Genomics and Human Genetics 18 189-200. (https://doi.org/10.1146/ annurev-genom-091416-035508)

Tremblay R, Dufort I \& Sirard MA 2017 Metabolic stress induces modifications in the epigenetic program of preimplantation bovine embryos. Molecular Reproduction and Development 85 117-127. (https://doi.org/10.1002/mrd.22941)

Van Soom A, Rijsselaere T \& Filliers M 2014 Cats and dogs: two neglected species in this era of embryo production in vitro? Reproduction in Domestic Animals 49 (Supplement 2) 87-91. (https://doi.org/10.1111/rda.12303)

Westhusin ME, Pryor JH \& Bondioli KR 1991 Nuclear transfer in the bovine embryo: a comparison of 5-day, 6-day, frozen-thawed, and nuclear transfer donor embryos. Molecular Reproduction and Development 28 119-123. (https://doi.org/10.1002/mrd.1080280203)

Willadsen SM 1989 Cloning of sheep and cow embryos. Genome 31 956-962. (https://doi.org/10.1139/g89-167)

Yum S-Y, Youn K-Y, Choi W-J \& Jang G 2018 Development of genome engineering technologies in cattle: from random to specific. Journal of Animal Science and Biotechnology 9 16. (https://doi.org/10.1186/ s40104-018-0232-6)

Received 5 January 2018

First decision 15 February 2018

Revised manuscript received 3 April 2018

Accepted 10 April 2018 